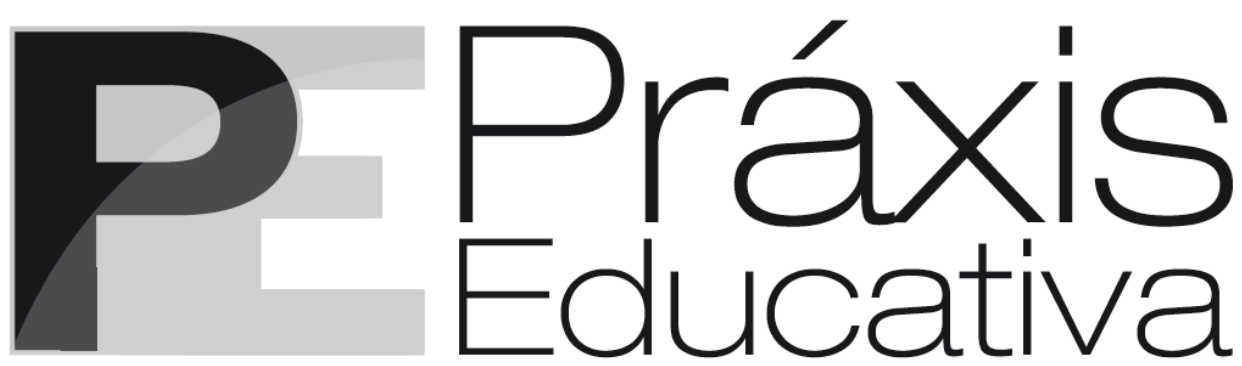

ISSN 1809-4031

elSSN 1809-4309

http://dx.doi.org/10.5212/PraxEduc.v.14n3.025

\title{
O escutismo na construção das cidadanias juvenis: concepções de política de jovens escuteiros e escuteiras
}

\section{Scouting in the construction of youth citizenships: conceptions of politics of young scouts}

\section{Escultismo en la construcción de las ciudadanías juveniles: concepciones de política de jóvenes escultistas}

\author{
Mariana Rodrigues* \\ Isabel Menezes ${ }^{* *}$ \\ Pedro D. Ferreira ${ }^{* * *}$
}

Resumo: A produção científica apresenta lacunas no que concerne a exploração dos potenciais contributos do escutismo na construção das subjetividades e das experiências cidadãs dos/as jovens envolvidos no movimento. Questionando o seu "lugar" na vivência quotidiana dos jovens escuteiros/as e assente em uma abordagem qualitativa, este estudo procura aprofundar o conhecimento sobre as concepções de política de 359 jovens escuteiros/as membros do Corpo Nacional de Escutas português, com idades entre os 15 e os 22 anos; explora, ainda, as condições sob as quais estes/as jovens aprendem o que significa ser um/a cidadão/ã em um contexto político democrático. Os resultados revelam que estes/as jovens apresentam diversas concepções de política com distintos níveis de complexidade e foco, variando entre o profundo desinteresse e a indiferença e a conceptualização da política como uma ação em diferentes esferas da sociedade. Contudo, a maioria dos/as participantes concebe a política como uma ação confinada ao aparelho governamental, que sustenta a organização social.

Palavras-chave: Escutismo. Discursos de jovens. Concepções de política.

\footnotetext{
* Investigadora Colaboradora do Centro de Investigação e Intervenção em Educação (CIIE) da Faculdade de Psicologia e Ciências da Educação da Universidade do Porto (FPCEUP), Porto, Portugal. Doutora em Ciências da Educação pela FCPCEUP. E-mail: <mrodrigues@fpce.up.pt>. ORCID: http://orcid.org/0000-0003-4183-4805

${ }^{* *}$ Professora Catedrática do Departamento de Ciências da Educação da FPCEUP e diretora do Programa Doutoral em Ciências da Educação da FPCEUP e investigadora integrada no CIIE. Doutora em Psicologia e agregada em Ciências da Educação pela FCEUP. E-mail: <imenezes@fpce.up.pt>. ORCID: https://orcid.org/0000-0001-90633773

*** Professor Adjunto do Departamento de Ciências da Educação da FPCEUP e investigador integrado no CIIE. Doutor em Psicologia pela FCEUP. E-mail: <pferreira@fpce.up.pt>. ORCID: https://orcid.org/0000-0002-50107397
}

Práxis Educativa, Ponta Grossa, v. 14, n. 3, p. 1270-1291, set./dez. 2019 Disponível em: <http://www.revistas2.uepg.br/index.php/praxiseducativa $>$ 


\begin{abstract}
The scientific production presents gaps concerning the exploration of the potential contributions of scouting in the construction of the subjectivities and citizenship experiences of the young people involved in the movement. Questioning their "place" in the everyday experiences of young scouts and based on a qualitative approach, this study seeks to deepen the knowledge about the conceptions of politics of 359 young scout members of the Portuguese Catholic Scout Association, aged between 15 and 22 years; it also explores the conditions under which these young scouts learn what it means to be a citizen in a democratic political context. The results reveal that these young people present different conceptions of politics with different levels of complexity and focus, varying between deep disinterest and indifference and a conception of politics as an action in the different spheres of society. However, most participants conceive politics as an action confined to the government apparatus, which supports social organization.
\end{abstract}

Keywords: Scouting. Young people's discourses. Conceptions of politics.

Resumen: La producción científica presenta vacíos en lo que concierne a la exploración de las potenciales contribuciones del escultismo en la construcción de las subjetividades y de las experiencias ciudadanas de los jóvenes involucrados en el movimiento. Cuestionando su "lugar" en la vivencia cotidiana de los jóvenes escultistas y basado en un enfoque cualitativo, este estudio busca profundizar el conocimiento sobre las concepciones de política de 359 jóvenes escultistas miembros del Cuerpo Nacional de Escultistas, con edades entre los 15 y los 22 años; explora, además, las condiciones bajo las cuales estos/as jóvenes aprenden lo que significa ser un/a ciudadano/a en un contexto político democrático. Los resultados revelan que estos/as jóvenes presentan diversas concepciones de política con distintos niveles de complejidad y foco, variando entre el profundo desinterés y la indiferencia y la conceptualización de la política como una acción en diferentes esferas de la sociedad. Sin embargo, la mayoría de los participantes concibe la política como una acción confinada al aparato gubernamental, que sostiene la organización social.

Palabras clave: Escultismo. Discursos de jóvenes. Concepciones de política.

\title{
Introdução
}

A investigação revela que governos, organizações e representantes políticos estão preocupados com os graus insatisfatórios de aceitação da democracia representativa, os baixos níveis de participação política dos/as cidadãos/ãs e o crescente desencantamento destes com a comunidade política que os/as representa (SCHULZ et al., 2010). Concretamente, os/as jovens são descritos/as frequentemente como demonstrando baixos níveis de compromisso, interesse e participação cívica e política (AMADEO et al., 2002; FAHMY, 2006; MENEZES, 2003; PUTNAM, 2000; RUSSEL, 2004; THEISS-MORE; HIBBING, 2005). Ao refletirem sobre essas fragilidades das sociedades democráticas contemporâneas, diversos agentes políticos e sociais justificam esses indicadores como reveladores do "défice" nos conhecimentos e nas capacidades democráticas dos/as cidadãos/ãs e no processo de implementação das políticas educativas (BIESTA, 2008, 2011; HEDTKE, 2013; SCHULZ et al., 2010; TOOTS, 2013).

A literatura também nos diz que os/as jovens aprendem sobre democracia por meio do envolvimento em práticas e processos quotidianos e da qualidade das próprias experiências enquanto cidadãos/ãs (DEWEY, [1916]1985; BIESTA, 2008; LIMA, 1999; McCOWAN, 2009). Múltiplos contextos de socialização, estruturalmente interligados, proporcionam experiências educativas e participativas a crianças e jovens que contribuem para a construção do sentido de si mesmos/as, enquanto pessoas e enquanto cidadãos/ãs em uma sociedade democrática (FERREIRA; COIMBRA; MENEZES， 2012; FLANAGAN， 2004; PUTNAM， 2000; QUINTELIER, 2008).

Perante esse enquadramento, tanto as políticas europeias como as nacionais enfatizam a necessidade de promover e suportar a participação ativa dos/as cidadãos/ãs no processo democrático, não só formalmente, como também através das comunidades locais e das

Práxis Educativa, Ponta Grossa, v. 14, n. 3, p. 1270-1291, set./dez. 2019 Disponível em: <http://www.revistas2.uepg.br/index.php/praxiseducativa> 
instituições da sociedade civil (CAETANO et al., 2012; RIBEIRO, 2014; ZIMENKOVA, 2013). Consequentemente, a participação voluntária juvenil em contextos associativos tem ganhado relevo, havendo evidências empíricas do impacto desses processos no seu desenvolvimento psicopolítico (PRILLELTENSKY, 2003; WATTS; FLANAGAN, 2007). A investigação tem revelado que a participação juvenil nesses contextos de associativismo voluntário afecta como compreendem a democracia e os seus princípios e valores, contribuindo para a promoção de conhecimentos, comportamentos e atitudes políticas (AZEVEDO, 2009; DELLI CARPINI; KEETER, 1996; FERREIRA, 2006; MALAFAIA, 2017; PARRY; MOYSER; DAY, 1992; QUINTELIER, 2008; VAN DER MEER; VAN INGEN, 2009; ZALLER, 1992). Diferentes organizações voluntárias proporcionam diferentes experiências, consequentemente exercem distintas e variadas influências nos seus diferentes membros (HUCKFELDT; IKEDA; PAPPI, 2004; PARRY; MOYSER; DAY, 1992; QUINTELIER, 2008). O potencial desenvolvimental dessas experiências associativas constituírem oportunidades de aprendizagem democrática, reflexividade política e governação depende da configuração institucional mais ampla que envolve o contexto, mas também dos seus mecanismos e das suas características internas (BOJE, 2008), particularmente a sua estrutura organizacional e objetivos como também das características individuais dos seus membros (PUTNAM, 1993; VAN DER MEER; VAN INGEN, 2009), a sua localização e a sua capacidade para ação coletiva (KAUFMAN, 2002; WARREN, 2001), a diversidade que caracteriza os seus membros (THEISS-MORSE; HIBBING, 2005) e das caraterísticas das atividades organizadas (BOHNERT; FREDRICKS; RANDALL, 2010; MAHONEY et al., 2005).

Em um estudo realizado em 17 países europeus, onde tentavam identificar a correlação entre o envolvimento associativo e a ação política, Van der Meer e Van Ingen (2009), embora não tenham encontrado evidências de relação causa-efeito entre envolvimento associativo e ação política, perceberam que a participação em organizações de interesse (e.g., sindicatos, organizações empresariais, profissionais ou de consumidores) e ativistas (e.g., ambientais ou humanitárias) demonstram ter maior impacto nos comportamentos políticos dos seus membros do que as organizações de lazer (e.g., associações desportivas, culturais e sociais).

Ellien Quintelier (2008) desenvolveu um estudo empírico em que pretendeu perceber que organizações voluntárias e características organizativas potenciam os comportamentos de participação cívica e política dos seus membros. A autora concluiu que "[...] organizações culturais, deliberativas e de ajuda são mais bem sucedidas do que grupos expressivos, éticoreligiosos e juvenis na socialização dos jovens na política" (QUINTELIER, 2008, p. 365). A autora acrescenta que os/as jovens que têm oportunidades para o desempenho de papéis de liderança e de organização de atividades tendem a demonstrar mais envolvimento cívico e político. A autora salienta ainda que as competências de organização e liderança facilitam o desenvolvimento de outras competências, que "são indiretamente úteis" na compreensão de discussões políticas complexas, na recolha de informação e no envolvimento nos debates políticos (QUINTELIER, 2008, p. 359).

A investigação revela também que a participação em contextos relacionais interpessoais e de índole comunitário influenciam o desenvolvimento de maior compaixão e interdependência (YOUNISS; YATES, 1996), de confiança interpessoal e social (QUINTELIER, 2008; SULLIVAN; TRANSUE, 1999) e da existência de sentido de pertença a uma ordem social mais ampla (FLANAGAN, 2004). Contudo, Van der Meer e Van Ingen (2009, p. 281) demostram que "[...] a correlação entre o envolvimento associativo e ação política não é explicada pela existência de competências cívicas e de consciência cívica". De qualquer forma, continua a ser escasso o conhecimento sobre as realidades em que diferentes pessoas se compreendem como cidadãos/ãs (JONES; GAVENTA, 2002).

Práxis Educativa, Ponta Grossa, v. 14, n. 3, p. 1270-1291, set./dez. 2019 Disponível em: <http://www.revistas2.uepg.br/index.php/praxiseducativa > 
Em Portugal, a investigação revela que a participação juvenil tende a acontecer em contextos associativos, nomeadamente de cariz desportivo, cultural, recreativo, de solidariedade social ou religioso (AZEVEDO, 2009; FERREIRA, 2006; MENEZES et al., 2005). Além de configurarem contextos ecologicamente complexos e significativos, dada a multiplicidade de interações e influências que neles se geram, as organizações escutistas constituem um dos maiores contextos juvenis de educação não-escolar (CUNHA, 2016; GRANJA, 2007; PALHARES, 2004, 2008; RODRIGUES, 2019). Mais concretamente, o Corpo Nacional de Escutas (CNE), contando em 2019 com 96 anos de existência, é a organização mais representativa em termos de afiliação, estimando cerca de 72.000 crianças, jovens e adultos associados em 2016. Contudo, constata-se que a produção científica sobre o escutismo é escassa (BROSTRÖM, 2012; MILLS, 2013; PROCTOR, 2009; WARREN, 2009), sendo negligenciado o papel do movimento escutista nos processos de socialização política de jovens. Este artigo pretende colmatar essa lacuna acerca do conhecimento, das disposições, das atitudes e dos valores de jovens escuteiros/as, explorando os potenciais contributos da vivência e da experiência do escutismo nos processos juvenis de socialização política e na promoção da qualidade do sistema democrático.

\section{Escutismo enquanto contexto de participação e educação}

Sendo o escutismo um movimento associativo que persistiu ao longo de todo o século XX e continuando a ser uma presença nos nossos dias, é intrigante perceber que não lhe é dedicada muita atenção ao nível da produção e interesse científico, tendo em conta que questões centrais na história contemporânea como "educação, o ambiente local e global, militarismo, totalitarismo e liberdade, género, raça, sexualidade e classe, tal como fé e secularização" estão intimamente ligadas à própria história do escutismo (WARREN, 2009, p. xi). A investigação realizada no domínio do escutismo incide essencialmente sobre a bibliografia de atores importantes na história do movimento (MILLS, 2013; BLOCK, 2009), negligenciando “[...] o papel das materialidades, das práticas corporais e do desempenho nos seus espaços organizacionais" (BLOCK, 2009, p. 121). Mostra-se, portanto, pertinente colmatar essa lacuna na compreensão dos contributos do escutismo na construção das cidadanias dos/as jovens escuteiros/as, questionando o "lugar" do escutismo nos seus discursos e nas suas concepções (PALHARES, 2008).

A história da génese do movimento é amplamente explorada pela literatura (BROSTRÖM, 2012; GRANJA, 2007; MAIA, 2009; MILLS, 2013; PALHARES, 2004; PROCTOR, 2009; SUNDMARK, 2009; VANHOENACKER, 2011; VICENTE, 2004). O escutismo, enquanto movimento voluntário organizado, conta com uma história com mais de 100 anos. Em 1907, o seu fundador, o então general inglês Robert Baden-Powell (1857-1941) mobilizou um grupo de 20 jovens rapazes para a realização de um acampamento em Brownsea Island, na Inglaterra, onde tiveram a oportunidade de participar de uma variedade de atividades, tais como "[...] acampar, observar, artesanato, cavalaria, salva-vidas e exercícios em patriotismo" (SUNDMARK, 2009, p. 112). Tendo sido considerado uma experiência de sucesso, esse evento marcou indubitavelmente o início da história do movimento escutista (SUNDMARK, 2009; MILLS, 2013). Após esse acampamento, Baden-Powell inicia a publicação quinzenal de parcelas da obra de "Escutismo para Rapazes: um Manual para a Instrução na Boa Cidadania", que seria compilada e publicada em um só volume em 1908, alcançando um "sucesso instantâneo" (SUNDMARK, 2009, p. 112).

No prefácio da sua obra Escutismo para rapaz̨es: um manual para a instrução na boa cidadania, Baden-Powell afirma que mais do que "uma revolução na educação", o escutismo pretende assumir-se como um contexto educativo complementar à escola assente em uma abordagem

Práxis Educativa, Ponta Grossa, v. 14, n. 3, p. 1270-1291, set./dez. 2019 Disponível em: <http://www.revistas2.uepg.br/index.php/praxiseducativa> 
prática capaz de "[...] colmatar algumas lacunas inevitáveis do currículo escolar ordinário" (BADEN-POWELL, 1908, n.p.). Baden-Powell foi inspirado pelas ideias liberais de Ernest Thompson Seton (BLOCK, 2009) e pelos contributos teóricos de percussores do movimento da Escola Nova, nomeadamente de Maria Montessori, impulsionadora do desenvolvimento de capacidades práticas de vida, e de John Dewey, defensor dos benefícios do trabalho colaborativo (BLOCK, 2009; KIERSTEAD, 1981; PROCTOR, 2009).

O escutismo tem como principal propósito "ajudar", "treinar" e "qualificar" crianças e jovens para se tornarem cidadãos "bons" e "úteis" (BADEN-POWELL, 1908). Contudo, que concepção de educação, cidadania e democracia está presente no discurso e na obra do fundador do escutismo, atendendo às especificidades do seu contexto sócio-histórico? Sendo o escutismo concebido como uma escola de cidadania e democracia (MILLS, 2013; PALHARES, 2008) por meio da experiência ao ar livre, de atividades de lazer (BROSTRÖM, 2012; WARREN, 2009), a educação para a cidadania deve preparar crianças e jovens, por intermédio da aquisição ativa de capacidades, conhecimentos e valores morais, no sentido de prestarem um serviço eficiente à comunidade (PROCTOR, 2009: WITTEMANS, 2009). A concepção de cidadania proclamada por Baden-Powell assenta em três dimensões: dever para consigo mesmo/a, dever para com os/as outros/as e dever para com Deus (MILLS, 2012; WITTEMANS, 2009), enfatizando a importância do autocontrolo, autodisciplina, lealdade, veracidade, autossugestão e autocura (BADEN-POWELL, 1922). O fundador do escutismo argumenta que "[...] um homem [sic] que se controle a ele mesmo, a sua raiva, o seu medo, as suas tentações - tudo de facto, exceto a sua consciência e a sua vergonha" (BADEN-POWELL, 1922, p. 47). Baden Powell apresenta uma abordagem "totalitária", mas "acima de tudo universalizante" de educação para a cidadania (WITTEMANS, 2009, p. 57), isto é, por um lado, a ideia de que todos as pessoas têm o dever de contribuir, por meio das suas ações, em benefício do bem-estar e da coesão social na sua comunidade local, no seu país e no mundo; por outro lado, a ideia da igualdade entre todos/as os/as cidadãos/ãs. Assim, o movimento escutista é descrito como um contexto de educação não formal e informal, em que "os/as escuteiros/as são universalizados/as" como pessoas que trabalham para "o bem maior" (MILLS, 2013, p. 125), nomeadamente "através do serviço à comunidade, realizando boas ações, e do patriotismo" (WITTEMANS, 2009, p. 57). Tendo sido originalmente concebido e operacionalizado como um contexto social privilegiado para a produção de conhecimento e significados, como também as suas práticas e os seus discursos têm sido centrais na "(re)produção" de certo tipo ideal de sujeito-cidadão há mais de um século (MILLS, 2013; SPRINGHALL, 1977).

A disseminação do escutismo foi rápida e crescente pela Europa e pelo mundo. Recuando um pouco às origens do $\mathrm{CNE}$, o movimento escutista católico português, o primeiro agrupamento surgiu em 27 de maio de 1923, na cidade de Braga, sendo impulsionado pelo Arcebispo Primaz de Braga D. Manuel Vieira de Matos e o seu secretário Dr. Avelino Gonçalves, “[...] após terem contatado durante um Congresso Eucarístico Internacional em Roma, em 1922 com um desfile de 20.000 escuteiros e de presenciar o trabalho realizado pelos Escuteiros Católicos Italianos" (GRANJA, 2007, p. 41). Na página oficial do CNE, que se apresenta como parte integrante de um movimento mundial, assume-se como um contexto de associativismo voluntário, orientado para a educação não formal de jovens, sem fins lucrativos, não-político e não-governamental. O projeto educativo do CNE:

Práxis Educativa, Ponta Grossa, v. 14, n. 3, p. 1270-1291, set./dez. 2019 Disponível em: <http://www.revistas2.uepg.br/index.php/praxiseducativa > 
[...] aposta no aprender fazendo. Através de atividades que são projetadas, desenvolvidas e implementadas tendo por base o método do projeto e o trabalho em equipa, procura-se que os escuteiros trabalhem as seguintes áreas de desenvolvimento: carácter, afetiva, intelectual, física, social e espiritual. Consoante as idades, estas atividades podem envolver construções, jogos, exploração, raides ou serviço comunitário, mas, acima de tudo, pretende-se que estas reflitam os desafios que os jovens encontram durante todo o seu percurso de vida, preparando-os para uma cidadania ativa, relação com o próximo, sustentabilidade ambiental e desenvolvimento pessoal integral. (CNE, 2016, n.p.).

Rodrigues Menezes e Ferreira (2015) constataram que a cultura organizativa do CNE apresenta uma estrutura hierarquizada, fundada nos princípios da democracia representativa. Crianças e jovens escuteiras/os, entre seis e 22 anos, não podem participar diretamente nos processos de discussão que acontecem no nível superior de decisão, onde são abordados temas e problemáticas, que diretamente os/as condicionam como seus/suas principais destinatários/as. Elas e eles atingem a cidadania plena por volta dos 22 anos, quando completam os seus percursos na associação de escuteiros/as. No centro do ideário educativo escutista, reside uma noção de criança e de jovem como projeto de cidadão/ã em desenvolvimento, isso quer dizer que escuteiros/as são envolvidos/as em experiências desenhadas para que desenvolvam conhecimento, capacidades, disposições e valores considerados essenciais para o exercício ativo das suas cidadanias na futura vida adulta, enquanto no presente treinam ativamente no cumprimento das suas responsabilidades como escuteiros/as. Durante um longo e contínuo processo de socialização, que busca claramente um tipo de cidadania, a formação do carácter e da identidade individual e coletiva de crianças e de jovens é influenciada por um sistema de valores, normas, símbolos e práticas que substanciam um código moral de conduta singular em torno do que significa ser "bom/a" cidadão/ã. Westheimer e Hahne (2004, p. 238) lembram-nos que "[c]oncepções de 'boa cidadania' implicam concepções de boa sociedade", que, por sua vez, veiculam diferentes formas e níveis de participação. Entretanto, que tipo de subjetividade se deseja formar por meio do escutismo? Essencialmente alguém que tem uma vida exemplar e solidária em conformidade com a lei escutista, servindo ativa e voluntariamente as suas comunidades, portanto movido/a por interesses altruístas na procura do bem-comum e da coesão social. Alguém que respeita e exerce os princípios da democracia representativa, elegendo os seus representantes e colaborando com a voz da maioria. Durante 16 anos de escutismo, é comunicado continuamente a crianças e jovens que devem estar sempre alerta para o cumprimento dos seus deveres, procurando deixar o mundo melhor que o encontraram, o que implica que assumam o papel que têm reservado no mundo e o desempenhem da melhor maneira, dentro e fora do tempo e do espaço do escutismo (RODRIGUES; MENEZES; FERREIRA, 2015).

Posto isso, o que nos diz a produção científica sobre os contributos do escutismo para o desenvolvimento sociopolítico juvenil? Existem evidências empíricas dos múltiplos e dos positivos contributos da participação no contexto escutista, em que os/as jovens escuteiros/as tendem a exibir maiores níveis de comportamentos pró-sociais altruístas (RUIZ-OLIVARES; PINO; HERRUZO, 2013), sentido de comunidade (CUNHA, 2016), tolerância, solidariedade e de promoção de uma cultura de paz (MAYOR, 1995), como também de entreajuda, respeito pela vida humana e animal e pelo ambiente (PALHARES, 2008), autoconfiança, respeito pela autoridade, sentido de serviço à comunidade, autossuficiência (PROCTOR, 2009), sentido de identidade (WARREN, 2009) e capacidade de liderança (JABR, 1998). Quando comparada com outras associações voluntárias, as organizações juvenis, como o escutismo, não potenciam a participação política (QUINTELIER, 2008), apesar do forte compromisso pessoal dos/as jovens e de promoverem o desenvolvimento de algumas capacidades políticas relevantes (FRISCO; MULLER; DODSON, 2004). Palhares (2008) descreve “[...] a atribuição de responsabilidades no

Práxis Educativa, Ponta Grossa, v. 14, n. 3, p. 1270-1291, set./dez. 2019 Disponível em: <http://www.revistas2.uepg.br/index.php/praxiseducativa> 
seio da patrulha, o espírito de colaboração e de cooperação que emergia nos jogos, nas atividades e nos vários cenários de interação escutista", como estratégias educativas orientadas para "a consecução de objectivos comuns e partilhados", constituindo, portanto, “[...] valiosos contributos para a realização da aprendizagem dos sentidos da democracia e da experiência da cidadania democrática" (PALHARES, 2008, p. 120-121). Assim sendo, o presente estudo pretende aprofundar o conhecimento sobre as concepções de política de jovens escuteiros/as, explorando as formas como esses/as jovens aprendem sobre democracia e exercem as suas cidadanias em um contexto político democrático.

\section{Desenho metodológico do estudo}

\section{Amostra e procedimento de recolha de dados}

Como referido anteriormente, a associação escuteira católica portuguesa, CNE, constitui objeto deste estudo. Considerando que o CNE é composto por 1022 agrupamentos que se distribuem diferentemente ao longo das 20 regiões do território nacional, uma amostra de 122 agrupamentos foi selecionada por meio de um processo de amostragem probabilística estratificada. Assim, deste estudo, participaram 359 jovens escuteiros/as (58,5\% do sexo feminino, $\left.M_{\text {idade }}=18,35, D P=2,09\right)$, com idades compreendidas entre os 15 e os 22 anos. Adicionalmente, o tempo de envolvimento na associação dos/as jovens inquiridos/as varia entre 0 e 17 anos. Os/as jovens escuteiros/as inquiridos/as tornaram-se membros do CNE, em média, há 9 anos. A seleção da faixa etária está em consonância com estudos anteriores, em que se entende que os/as jovens desenvolvem as suas identidades políticas e padrões de comportamento político, particularmente, a partir dos 14 anos (AMADEO et al., 2002).

Depois de recolhidos os consentimentos informados e assinados pelos/as participantes (ou respetivos pais ou representantes legais em caso de serem menores de idade), estes/as responderam a um inquérito por questionário individualmente em formato papel ou online, conforme a vontade expressa pelo agrupamento. No sentido de facilitar a administração coletiva e a resposta individual dos participantes, foram escritas instruções estandardizadas de suporte ao preenchimento do questionário e realçado quer o anonimato e a confidencialidade das respostas quer o carácter voluntário da participação.

\section{Instrumento e procedimento de análise de dados}

Os dados apresentados neste artigo foram obtidos por meio de aplicação de um inquérito por questionário que, entre outros elementos, contemplava duas questões abertas que possibilitaram a livre expressão dos/as participantes sobre as suas concepções de política e da sua importância na vida em sociedade. O material empírico recolhido foi analisado recorrendo à análise temática aplicada, um método analítico qualitativo que proporciona uma abordagem "rigorosa" e "indutiva", baseada em um "conjunto de procedimentos desenhados para identificar e examinar temas a partir de dados textuais de uma forma que é transparente e credível" (GUEST; MACQUEEN; NAMEY, 2012, p. 15). Por se tratar de perguntas abertas, foi possível obter um rico e extenso espólio de dados. Assim, as respostas dos/as participantes foram agrupadas em cinco temas, com um nível de complexidade crescente, consoante os significados que estes atribuem ao conceito de política e à sua importância social: 1) ausência de opinião; 2) desinteresse/indiferença; 3) política como ação governamental; 4) política como ação na esfera pública; e 5) política como ação nas diversas esferas da existência social.

Práxis Educativa, Ponta Grossa, v. 14, n. 3, p. 1270-1291, set./dez. 2019 


\section{Resultados}

Antes de explorarmos detalhadamente os resultados da análise qualitativa dos discursos dos/as jovens participantes no que concerne as suas concepções de política, começamos por apresentar uma informação quantitativa sobre a distribuição da amostra pelos cinco temas de análise, segundo sexo e grupo etário (Tabela 1).

Tabela 1 - Caracterização da amostra segundo a concepção de política, por grupo etário e sexo $(\mathrm{n}=359)$

\begin{tabular}{|c|c|c|c|c|}
\hline \multirow[b]{2}{*}{ Concepção de Política } & \multirow{2}{*}{$\begin{array}{l}\text { Grupo } \\
\text { etário }\end{array}$} & \multicolumn{2}{|c|}{ Sexo } & \multirow[b]{2}{*}{ Total } \\
\hline & & feminino & masculino & \\
\hline \multirow[t]{2}{*}{ Ausência de opinião } & $15-17$ & $8(2,23 \%)$ & $3(0,84 \%)$ & $11(3,06 \%)$ \\
\hline & $18-22$ & $8(2,23 \%)$ & $1(0,28 \%)$ & $9(2,54 \%)$ \\
\hline \multirow[t]{2}{*}{ Desinteresse/Indiferença } & $15-17$ & $11(3,06 \%)$ & $9(2,54 \%)$ & $20(5,57 \%)$ \\
\hline & $18-22$ & $16(4,46 \%)$ & $11(3,06 \%)$ & $27(7,52 \%)$ \\
\hline \multirow[t]{2}{*}{ Política como ação governamental } & $15-17$ & $52(14,48 \%)$ & $29(8,08 \%)$ & $81(22,56 \%)$ \\
\hline & $18-22$ & $76(21,17 \%)$ & $58(16,16 \%)$ & $134(37,33 \%)$ \\
\hline \multirow[t]{2}{*}{ Política como ação na esfera pública } & $15-17$ & $12(3,34 \%)$ & $12(3,34 \%)$ & $24(6,69 \%)$ \\
\hline & $18-22$ & $25(6,96 \%)$ & $19(5,29 \%)$ & $44(12,26 \%)$ \\
\hline \multirow[t]{2}{*}{ Política como ação na esfera social } & $15-17$ & $0(0,00 \%)$ & $2(0,56 \%)$ & $2(0,56 \%)$ \\
\hline & $18-22$ & $2(0,56 \%)$ & $5(1,39 \%)$ & $7(1,95 \%)$ \\
\hline & Total & $210(58,49 \%)$ & $149(41,51 \%)$ & $359(100,00 \%)$ \\
\hline
\end{tabular}

Fonte: Elaborada pelos autores.

Como podemos observar na Tabela 1 , à medida que aumenta a complexidade do conceito de política, ou seja, quando nos deslocamos da concepção de política como ação governamental (processo exclusivo aos grupos partidários) até à concepção de política como ação na esfera social (processo que engloba todos os grupos sociais e pessoas), verificamos um decréscimo considerável na menção aos temas. Adicionalmente, podemos observar também que os/as participantes que reportaram não ter uma opinião formada sobre o conceito de política, ou que se afirmaram como desinteressados/as e/ou indiferentes em relação a ela, tendem a ser do sexo feminino, independentemente do grupo etário. A concepção da política como ação do governo e dos grupos parlamentares é a mais frequente nos discursos dos/as participantes, independentemente do sexo e do grupo etário. Em geral, podemos afirmar que os/as participantes mais velhos/as, entre 18 e 22 anos, tendem a apresentar concepções de política mais complexas do que os/as mais novos/as, entre 14 e 17 anos.

\section{Ausência de opinião: a politica é um tema complexo, mas importante}

Uma jovem de 15 anos afirmou: "Não sei o que significa política". Tal como essa jovem, esse tema integra todos/as os/as jovens que não têm uma opinião formada sobre política, não apresentando qualquer definição dela. Uns/umas jovens argumentam que não conseguem ou não sabem definir política, em geral por considerarem um tema complexo. Outros/as aproveitam para justificar a falta de conhecimento e entendimento sobre política como resultante da incapacidade ou desinteresse dos agentes de socialização política (e.g., pais, escola, media, CNE)

Práxis Educativa, Ponta Grossa, v. 14, n. 3, p. 1270-1291, set./dez. 2019 Disponível em: <http://www.revistas2.uepg.br/index.php/praxiseducativa $>$ 
na apresentação e discussão do tema. Esses/as jovens consideram que a política deveria ser um tema abordado de uma forma clara e desde cedo junto aos mais jovens:

\footnotetext{
"Não sei bem o que é a política porque na minha comunidade não lhe dão muita importância e não a transmitem aos jovens. Sim, se não houver política a sociedade não vai ser organizada." (jovem mulher, 16 anos).

"A política é explicada de modo complexo e não simples... deviam ensinar questões políticas mais cedo" (jovem mulher, 19 anos).
}

Paradoxalmente, apesar de não apresentarem uma definição concreta de política, esses/as jovens tendem a considerar que é uma atividade importante para que a vida social aconteça de uma forma organizada e regrada.

\section{Desinteresse/Indiferença: a política não serve para nada}

Esse tema engloba os/as participantes que se mostram desinteressados/as ou indiferentes em relação à política. Eles/as têm em comum não só uma evidente antipatia pela política, como também uma percepção generalizada de que é algo negativo. Contudo, a falta de conexão com a política é expressa de diferentes formas. Por exemplo, uma jovem de 17 anos afirma que a política não significa "nada" para si e não a "afeta minimamente". Como essa jovem, outros/as participantes justificam a sua indiferença pela política aludindo à irrelevância desta nas suas vidas, sendo considerada "uma inutilidade" e, portanto, não é "importante porque simplesmente não está cá a fazer nada" (rapariga, 18 anos). Em geral, esses/as jovens tendem a definir o conceito de política em termos bastante limitados, frequentemente recorrendo a críticas negativas aos políticos e ao trabalho que estes desenvolvem:

"Uma mentira consecutiva e bem disfarçada. Na minha perspectiva, [a política na vida em sociedade] não faz muita diferença" (jovem mulher, 19 anos).

“É tudo corrupção. A política é manhosa e para mim muitas vezes não é justa. Para mim não faz diferença" (jovem mulher, 17 anos).

Outros/as participantes evidenciam algum cinismo político, ou seja, esses/as jovens fazem questão de expor o total desinteresse na política; no entanto, tecem duras críticas ao desempenho dos/as representantes políticos/as, espelhadas em uma profunda desconfiança e desrespeito em relação a eles/as:

\footnotetext{
"Detesto política. Os políticos são todos uns borra botas, puxam sempre a 'brasa para a sua sardinha'. Para mim política não me diz nada. Na política há o 'animal grande' e atrás dele andam os parasitas que mal sabem o que andam lá a fazer” (jovem mulher, 19 anos).

"Roubo, Mentira, interesses pessoais. [A política] pode melhorar a qualidade de vida das pessoas, e ajuda na organização. Em Portugal apenas nos roubam...” (jovem homem, 22 anos).
}

De um modo geral, os/as participantes indiferentes ou desinteressados/as tendem a frisar que a sua débil conexão com a política resulta do facto de se sentirem excluídos/as dos processos políticos. Esse sentimento de exclusão dos/as jovens é justificado com base em diferentes argumentos. Muitos dos discursos recolhidos dão conta do baixo sentido de eficácia política, interna e externa, que caracteriza muitos/as dos/as jovens que se mostram desinteressados ou indiferentes à política, como pretende demonstrar os exemplos seguintes: 
"Não tenho uma ideia sobre política. Não podemos fazer nada para mudar a sociedade através da política" (jovem mulher, 16 anos).

"Interessava-me mais se fossem pessoas interessadas em gerir e melhorar a situação do país/concelhos/freguesias" (jovem mulher, 21 anos)

“[...] cada vez mais a sociedade se está revoltando mais e mais” (jovem mulher, 19 anos).

Enquanto o primeiro excerto pretende ilustrar o baixo sentido de eficácia interna, isto é, a percepção individual da jovem acerca da sua incapacidade para influenciar positivamente a realidade social através da política; os segundo e terceiro excertos são exemplificativos do sentido de eficácia externa, sendo notório que essas jovens não confiam na capacidade ou no interesse do sistema político e dos/as seus/suas representantes de responderem às necessidades e reivindicações dos/as cidadãos/ãs.

Há também uma ideia generalizada entre os/as jovens participantes de que as oportunidades de participação na vida política estão circunscritas ao exercício do voto nas eleições. Por um lado, os mais jovens, menores de 18 anos, consideram que somente depois de atingirem a idade mínima para votar poderão interessar-se pela política:

"Sinceramente não sei, a política neste momento não é algo importante para mim, aliás nem posso votar porque haveria de me importar?” (jovem mulher, 15 anos).

No caso dos/as jovens participantes mais velhos/as, apesar de se mostrarem alheios à política, afirmam que participam regularmente nas eleições, desde que atingiram legalmente esse direito:

"Não percebo muito do assunto, mas gostaria de perceber mais. No entanto, voto sempre que é necessário desde os meus 18 anos. Considero [a política importante], apesar de não fazer parte da minha vida na sociedade” (jovem mulher, 22 anos).

Adicionalmente, alguns dos/as jovens inquiridos/as, entre os 15 e os 17 anos, justificam a falta de interesse na política, reforçando a escassez de oportunidades de participação, porém acrescentando que, atendendo às suas idades, estão mais focados/as noutros assuntos externos à política e mais prioritários nas suas vidas.

"[A política] não significa nada porque os jovens não podem votar, logo, não estão envolvidos suficientemente para ter uma perspectiva acerca da política, para além disso tendo em conta a nossa idade preocupámo-nos mais com outras coisas do que com política o que talvez esteja errado" (jovem homem, 17 anos).

\section{Política como ação governamental: um meio exclusivo aos grupos partidários}

A concepção dominante de política nos discursos dos/as jovens participantes surge associada à ação do aparelho governamental, por meio das suas instituições, entidades e grupos formais, que sustenta a organização da sociedade:

“Consiste num ‘órgão’ a que cabe a organização da sociedade” (jovem mulher, 16 anos).

"[É] tudo o que passa dentro do governo, assembleias que envolva o nosso país ou outros" (jovem homem, 15 anos).

Além de ser definida como uma atividade altamente restritiva e confinada à ação do governo, ou seja, a política "é uma ciência/arte que dá poder a um grupo determinado de pessoas para tomarem decisões pela nação" (jovem homem, 18 anos), muitos/as participantes

Práxis Educativa, Ponta Grossa, v. 14, n. 3, p. 1270-1291, set./dez. 2019 Disponível em: <http://www.revistas2.uepg.br/index.php/praxiseducativa> 
acrescentam que, em um contexto de democracia representativa, os/as representantes políticos/as são eleitos/as e incumbidos/as do exercício das funções de autoridade para tomar decisões coletivas e estabelecer planos de ação que visem o bem-estar de toda a comunidade:

\begin{abstract}
"Uma forma de controlar e tomar conta de uma nação ou comunidade, de modo a poder controlar alguns aspectos relacionados com a mesma, como os gastos financeiros. Sem a política tornava-se ainda mais difícil gerir todas as burocracias relacionadas com a comunidade [...], é sempre necessário haver um porta-voz que consiga representar o povo" (jovem mulher, 18 anos).

"É uma atividade que, sendo exercida por pessoas com caráter, é o motor impulsionador da nossa sociedade, trabalhando para o bem comunitário e sustentável de todos. Por ela se gera toda a economia e vida em sociedade, é importante que a política esteja ao serviço dos povos" (jovem homem, 22 anos).
\end{abstract}

Ao conceberem a política como ação governamental, muitos/as participantes salientam a importância da existência de hierarquia na organização da vida em sociedade, assim o governo deve assumir o seu papel de liderança e controlo, restringindo os interesses individuais e fomentando a ordem e a coesão social por meio do estabelecimento de leis, que os cidadãos/ãs devem respeitar e às quais devem obedecer para que a vida em sociedade seja justa e harmoniosa:

“A política é uma 'ciência' que se ocupa de gerir uma sociedade de forma justa e equitativa. Em qualquer grupo de pessoas é necessário um líder que tome as decisões ou que dê a cara pelo grupo" (jovem mulher, 19 anos).

"A política serve para criar um sistema de regras às quais devemos obedecer a fim de não vivermos na anarquia total e para assim vivermos todos em total respeito" (jovem homem, 22 anos)

“A política diz respeito ao modo como a sociedade se organiza e, no fundo, se rege, é esperado que todos os que nela se envolvam (cidadãos) se preocupem com o que esta estipula para a sociedade. A política tem um papel fundamental na vida em sociedade, uma vez que 'pauta' as regras e as linhas pelas quais os cidadãos se devem reger. Só esta forma pode garantir a vivência em sociedade, mediante regras que caracterizam a política escolhida para uma sociedade em questão" (jovem mulher, 18 anos).

Para alguns/mas dos/as participantes que concebem a política como arte de governar, o governo não tem somente a função de tomada de decisões coletivas e de garantir o seu cumprimento; ele tem também a função de resolução de conflitos de interesses através do debate, de sua negociação e de sua conciliação, procurando respostas consensuais que visem o bem-estar social:

"É o órgão que debate temáticas do quotidiano para tentar chegar a um consenso sobre o que é melhor para o povo" (jovem homem, 15 anos).

"Sem política havia uma desorganização e muitos mais conflitos" (jovem mulher, 18 anos).

"A política é uma arte de negociação para compatibilizar interesses, ou seja, tentar construir uma sociedade em que se possa viver tranquilamente em que todos temos um objetivo comum" (jovem mulher, 19 anos).

"O papel da política é saber harmonizar a vida dos cidadãos pois cada um tem os seus próprios interesses e se não existisse ninguém a gerir da melhor forma possível estes interesses então a vida em sociedade não seria possível. Não conseguiríamos ter uma sociedade se cada um gerisse os seus interesses e liberdades pessoais da maneira que mais lhe era conveniente" (jovem mulher, 16 anos).

Práxis Educativa, Ponta Grossa, v. 14, n. 3, p. 1270-1291, set./dez. 2019 Disponível em: <http://www.revistas2.uepg.br/index.php/praxiseducativa > 
Contrariamente à perspectiva do governo como meio para a resolução de conflitos e estabelecimento do consenso social, alguns participantes revelam uma visão negativa da política por considerarem que esta constitui um contexto gerador de conflitos que ameaçam a estabilidade e a coesão social:

\begin{abstract}
“A política [...] causa muitos conflitos entre pessoas e leva muitas vezes as comunidades a ficarem divididas [...]. Muitas vezes os cidadãos de uma determinada comunidade não se podem ver uns aos outros, tudo por causa de política, mais especificamente dos partidos políticos, o que causa um mau ambiente entre as pessoas da comunidades, o que não é nada saudável, pois uma comunidade deveria ser unida" (jovem mulher, 16 anos).
\end{abstract}

Na percepção de muitos/as dos/as jovens que definem a política como ação do governo, essencialmente da responsabilidade dos políticos e dos grupos partidários, observa-se uma tendência para desenvolver uma visão negativa e pessimista da política, que é caracterizada como um contexto de corrupção, incompetência e abuso de poder. Perante esse cenário político de injustiça e desigualdade social, estes/as participantes mostram-se desconfiados, desiludidos/as e insatisfeitos/as por não sentirem que os/as jovens e a população em geral são efetivamente ouvidos/as e representados/as politicamente:

"Acho que quase todos estão descontentes com a política, portanto acho que nos dias
de hoje não é uma atividade importante porque o que parece é que os governadores
não querem ouvir a voz do povo" (jovem mulher, 17 anos).

"Seria bastante importante, se fosse uma política transparente, justa e coerente" (jovem homem, 20 anos).

"Política significa farsa, monte de mentiras, corrupção e atentado aos direitos humanos" (jovem homem, 22 anos).

Mais ainda, "concretamente em Portugal, existe um excesso colossal de burocracia e de assuntos fúteis que ganham prioridade face aos que realmente importam. O que resulta enfim, numa difícil e hesitante inserção da sociedade nos assuntos políticos" (jovem homem, 22 anos). Tal como esse jovem, em geral, outros/as jovens que concebem a política como um campo confinado à ação governamental, consideram que a corrupção e a ineficiência que envolvem a política nacional constituem as principais barreiras ao envolvimento e à participação política dos cidadãos portugueses.

\title{
Política como ação na esfera pública: um meio de discussão e negociação
}

Enquanto no grupo anterior a política é concebida como uma ação estritamente confinada ao exercício de autoridade do aparelho governamental, este grupo apresenta uma definição de política mais abrangente, concebendo a política como ação dos/as cidadãos/ãs, da sociedade civil e do governo:

\footnotetext{
"Por vezes pensamos que a política é apenas para aqueles que governam. Mas governanos a nós, por isso a política envolve todos e a opinião de toda a gente" (jovem mulher, 17 anos).

"Política é tudo o que está relacionado com a administração de algo. A política não é apenas relativa ao estado, mas também a toda e qualquer associação" (jovem homem, 19 anos).
}

Assim, a política é definida como ação na esfera pública, que constitui um meio para o debate de assuntos de interesse comum na regulação e na melhoria da vida pública:

Práxis Educativa, Ponta Grossa, v. 14, n. 3, p. 1270-1291, set./dez. 2019 Disponível em: <http://www.revistas2.uepg.br/index.php/praxiseducativa> 
O escutismo na construção das cidadanias juvenis: concepções de política de jovens escuteiros e escuteiras

"A política é uma das atividades mais nobres do ser humano, isto porque é através dela mesma que é possível a gestão daquilo que é comum e daquilo que é partilhado por uma comunidade, um país, ou mesmo por toda a população mundial" (jovem homem, 19 anos).

"É fundamental para manter todos os cidadãos ativos na sociedade, afinal de contas todos nós temos sempre uma palavra a dizer e trata-se de um interesse comum" (jovem homem, 18 anos).

“A política permite a organização e governação de um país, dando ênfase a questões económico-sociais de interesse público e da atualidade. Na política tomam-se decisões do interesse público. A sociedade rege-se por questões políticas" (jovem mulher, 22 anos).

Adicionalmente, em geral, os/as participantes que se inserem neste grupo reconhecem que a sociedade contemporânea é marcada por um intenso pluralismo e diversidade de interesses e opiniões:

"A política somos todos nós. São todos os nossos ideais e todas as nossas ideias para inovar a sociedade" (jovem mulher, 18 anos).

"Se todos tivéssemos os mesmos pontos de vista seria muito fácil legislar e até aplicar a justiça (por exemplo), porém também podemos dizer que é essa mesma diversidade de opiniões que nos define como seres racionais e livres, que procuram diariamente novas 'pistas' para seguir ou apenas refutar, levando avante o seu projeto de vida" (jovem homem, 16 anos).

Como tal, a política constitui o campo privilegiado para a deliberação e negociação das múltiplas perspectivas e intenções, constituindo um processo que envolve a interação e a participação democrática de diferentes pessoas na procura do bem comum e da justiça social:

"Consiste na capacidade de diferentes pessoas com diferentes ideias discutirem essas ideias, com o objetivo de melhorar a nossa sociedade" (jovem homem, 18 anos).

“A política é um meio pelo qual as pessoas podem discutir as suas ideias e torná-las, de certo modo, melhores após ouvir a opinião dos outros" (jovem mulher, 20 anos).

"Permite-nos partilhar pontos de vista, tomar decisões, tornar a sociedade numa sociedade justa e promover o bem estar comum" (jovem mulher, 20 anos).

\section{Política como ação na esfera social: um meio de interação social}

Esse tema é o menos presente nos discursos dos/as participantes. Essa concepção de política distingue-se das anteriores por considerarem que a política "é um 'elemento' que está intrínseco em todo nosso meio social" (jovem mulher, 17 anos). Esses/as jovens entendem que a política é o âmago de toda a interação social, quer seja pública ou privada, nacional ou internacional, formal ou informal, envolvendo necessariamente todas as pessoas, os grupos e as instituições governamentais e não-governamentais:

“A política é tudo o que se relaciona. A política não é só a relação entre governo e a população. $\mathrm{O}$ que há em comum em todas as políticas são as relações. Podem ser hierárquicas, ou não. O Estado somos todos nós, por isso, somos todos política. Como nos importamos com os nossos futuros profissionais e pessoais, temos que nos importar, em conjunto, com a nossa sociedade e quem comanda as políticas de decisão" (jovem homem, 21 anos).

"É o modo de gerir toda as bases para as interações sociais e económicas a um nível nacional e internacional" (jovem homem, 19 anos).

Práxis Educativa, Ponta Grossa, v. 14, n. 3, p. 1270-1291, set./dez. 2019 Disponível em: < http://www.revistas2.uepg.br/index.php/praxiseducativa > 


\section{Discussão}

Concluído este trabalho, importa fazer duas ressalvas. Em primeiro lugar, não podemos negligenciar os múltiplos contextos e agentes sociais que coexistem e constituem oportunidades para a aprendizagem cívica e vivência democrática dos/as jovens escuteiros/as (RODRIGUES; MENEZES; FERREIRA, 2018). Em segundo, a natureza do presente estudo não permite estabelecer relações de causa-efeito. Contudo, existem evidências dos potenciais contributos da cultura organizacional e educativa escutista na forma como esses/as jovens concebem a política e as suas cidadanias em um contexto político democrático.

Os resultados demonstram que os/as jovens escuteiros/as não podem ser caracterizados/as como um grupo homogéneo no que respeita às suas visões do que é a política, apresentando diversas concepções com distintos níveis de complexidade e foco, variando entre o profundo desinteresse e indiferença e a conceptualização da política como uma ação em diferentes esferas da sociedade. Embora reconhecendo as subjetividades presentes nos discursos dos/as jovens escuteiros/as, importa refletir sobre o facto da maioria dos/as participantes inquiridos/as conceberem a política como uma ação confinada ao governo, nomeadamente por meio dos seus grupos partidários e políticos. Assim, a maioria dos/as participantes entende imprescindível a existência de um governo, assente nos princípios da democracia representativa, eleito por intermédio do exercício do voto, em quem os cidadãos delegam o poder quer de decidir pelo coletivo quer de controlar a organização social, fomentando a ordem, a coesão e a justiça social. Se assim não fosse, entendem que as pessoas lutariam pelos seus próprios interesses, o que desembocaria na anarquia e no caos social. Consequentemente, esses/as jovens enfatizam a importância do respeito pela lei para uma vida harmoniosa em sociedade. Mais ainda, muitos/as participantes, quer os que entendem a política como ação governamental quer os que se mostram desinteressados/as ou indiferentes em relação a ela, consideram que os políticos não desempenham digna e responsavelmente os seus papéis; assim, essa visão negativa dos políticos parece ter repercussões na forma como percepcionam a política.

É legítimo e pertinente que assumamos que o $\mathrm{CNE}$ contribui para a construção das cidadanias juvenis através da promoção de um ideal de cidadão/ã, que condiciona os sentidos e significados que os/as jovens atribuem às suas cidadanias, mais precisamente ao que significa e é esperado de um/a "bom/a" cidadão/ã. Esse processo de socialização política acontece através de "[...] geografias morais que reforçam comportamentos, corpos e ambientes ideológicos, muitas vezes baseando-se em poderosas noções de si e do outro" (MILLS, 2013, p. 127). Essa concepção de cidadania emerge, simultaneamente, na relação com uma concepção de anticidadania (MATLESS, 1995; MILLS, 2013; LISTER et al., 2003). Em consonância com outros estudos (e.g., MALAFAIA, 2017; MENEZES et al., 2012), a ação política partidária é alvo de críticas. Neste estudo em particular, o/a cidadão/ã-político/a, enquanto representante da comunidade política partidária, é descrito/a por muitos/as jovens escuteiros/as como alguém que não cumpre o seu papel na sociedade, não respeitando a função para a qual foi democraticamente eleito/a, precisamente oposto àquilo que esses/as jovens entendem como um comportamento socialmente responsável e solidário. Desse modo, alguém que desempenha o seu papel no que diz respeito a fazer do mundo um lugar melhor, mas também alguém que ajuda outras pessoas, sem esperar ser paga/o ou recompensada/o por isso. Alguém com valores, motivações e práticas de cidadania que são contrastantes, ou até contraditórias, em relação àquelas que caracterizam os membros da comunidade escutista, tendendo a infringir o código moral da lei escutista e a denegrir a reputação da comunidade que representam. Podemos assumir que ser escuteiro/a implica conformar-se com um modelo de cidadania, enquanto simultaneamente desenvolve expectativas e julgamentos de valor acerca do comportamento de

Práxis Educativa, Ponta Grossa, v. 14, n. 3, p. 1270-1291, set./dez. 2019 Disponível em: <http://www.revistas2.uepg.br/index.php/praxiseducativa> 
outros/as cidadãos/ãs dentro e fora do escutismo (RODRIGUES; MENEZES; FERREIRA, 2015).

Esta investigação permitiu-nos compreender como ideias de política são comunicadas e reproduzidas, mas também como essas ideias se legitimam e são amplificadas pelo contexto escutista. Ao longo deste trabalho de investigação, fomos encontrando evidências mais ou menos explícitas de uma "cultura de evitamento político", que se traduz na forma "[...] como alguns tipos de ideias são filtrados sistematicamente de circulação" (ELIASOPH, 1998, p. 480). O CNE apresenta-se como uma associação de carácter não-político, desmarcando-se oficialmente de qualquer identificação político-partidária, sendo proibido “[...] usar ou revelar a qualidade de Escuta em manifestações de carácter político-partidário" (Regulamento interno do CNE, Art. ${ }^{\mathrm{a}}$, alínea 3). Por um lado, estamos a falar de uma organização que, nos últimos 95 anos, tem existido sob diferentes enquadramentos políticos, considerando importante afirmar e assegurar um afastamento da política partidária. Esse enquadramento legal pode sugerir não só uma associação entre política e atividade política partidária, como também transmitir uma visão negativa da política enquanto arena problemática que pode corromper a integridade moral e denegrir a imagem social do/a cidadão/ã-escuteiro/a. Embora muitos factores sociais, como, por exemplo, os media (MEDINA, 2006), contribuam para a formação da imagem social dos políticos, parece plausível afirmar que os constrangimentos legais impostos pela associação escuteira afetam e influenciam a concepção de política e de políticos dos/as jovens escuteiros/as. Por outro lado, esses/as jovens tendem não só a evitar falar do seu posicionamento político, como também a afirmar uma falta de conhecimento, interesse e atenção em assuntos políticos. Ao "[...] tentarem preocupar-se com as pessoas, mas não com a política, significa tentar limitar as suas preocupações a questões sobre as quais eles/as sentem que podem 'realisticamente' fazer a diferença na vida das pessoas" (ELIASOPH, 1998, p. 13). Por oposição à política, que é um campo controverso que pode abalar o sentido de comunidade e de eficácia política desses/as jovens, o serviço voluntário à comunidade por meio de ações coletivas, definidas como apolíticas, pode trazer um forte sentimento de realização e de satisfação.

\section{Considerações finais}

O reconhecimento do papel do CNE na construção das cidadanias juvenis, promovendo a capacidade de mobilização de milhares de jovens em ações que os/as desafiam e os/as colocam em contato com oportunidades reais de coletivamente refletirem sobre os seus papéis e lugares nas suas comunidades, convocou a nossa atenção para explorar o lugar do escutismo nos discursos juvenis sobre política e o seu papel social.

As experiências individuais e coletivas são influenciadas pelos valores da cultura política, organizacional e educativa do contexto onde estas ocorrem (BRANCO; DOMINGUES, 2015; SEHR, 1997). Não esqueçamos que existe uma contínua transmissão de mensagens tácitas sobre normas, princípios, valores e disposições hegemónicas, que não foram expressamente explicitadas ou intencionalizadas no projeto educativo (APPLE, 1982). Essas mensagens condicionam a forma como crianças e jovens se concebem como pessoas e cidadãos/ãs (BIESTA, 2008; FREIRE, 1970). Por outras palavras, crianças e jovens são ensinadas/os e aprendem acerca do seu lugar ou função na sociedade, desenvolvendo diferentes concepções e relações de poder, e modos de pensar a organização social (GIROUX, 1981).

São incontornáveis os contributos do escutismo nos discursos de muitos/as jovens escuteiros/as; contudo, importa ter presente que entre aquilo que é educativamente desejável e promovido pelas políticas e práticas escutistas e aquilo que é efetivamente aprendido ou valorizado pelos/as jovens escuteiros/as, existe uma diferença que pode ser mais ou menos

Práxis Educativa, Ponta Grossa, v. 14, n. 3, p. 1270-1291, set./dez. 2019 Disponível em: <http://www.revistas2.uepg.br/index.php/praxiseducativa > 
significativa. Os resultados permitem contrariar a retórica dominante que tende a caracterizar a comunidade de jovens escuteiros/as como uma massa homogénea e estática de indivíduos (PALHARES, 2008). Esses/as jovens são pessoas distintas, além de escuteiros/as, são também filhos/as, amigos/as, estudantes e utilizadores/as de Internet. Além disso, não esqueçamos a bagagem experiencial e cultural que cada jovem transporta consigo entre os seus contextos quotidianos, condiciona a forma que este/a percebe e atribui significado às experiências vividas.

\section{Referências}

AMADEO, J.-A. et al. Civic knowledge and engagement: An IEA study for upper secondary students in sixteen countries. Amsterdam: International Association for the Evaluation of Educational Achievement (IEA), 2002.

APPLE, M. Education and power. Boston: Routledge and Kegan Paul, 1982.

AZEVEDO, C. N. Experiências de participação dos jovens: um estudo longitudinal sobre a influência da qualidade da participação no desenvolvimento psicológico. 2009. 494 f. Tese (Doutorado em Psicologia) - Universidade do Porto, Porto, 2009.

BADEN-POWELL, R. Scouting for boys: Handbook for Instruction in Good Citizenship through Woodcraft. London: Windsor House, Bream's Buildings, 1908.

BADEN-POWELL, R. Rovering to Success: A Guide for Young Manhood London: H. Jenkins, 1922.

BIESTA, G. J. J. A school for citizens: Civic learning and democratic action in the learning democracy. In: LINGARD, B.; NIXON, J.; RANSON, S. (Orgs.). Transforming learning in schools and communities. London: Continuum, 2008. p. 170-183.

BIESTA, G. J. J. Learning democracy in school and society: Education, lifelong learning and the politics of citizenship. Rotterdam: Sense Publishers, 2011.

BLOCK, N. A well where others may drink: 100 years of scouting history. In: BLOCK, N.; PROCTOR, T. (Orgs.). Scouting frontiers: Youth and the Scout Movement's first century. Newcastle: Cambridge Scholars Publishing, 2009. p. 2-27.

BOHNERT, A.; FREDRICKS, J.; RANDALL, E. Capturing unique dimensions of youth organized activity involvement: theoretical and methodological considerations. Review of Educational Research, v. 80, n. 4, p. 576-610, dez. 2010. DOI: https://doi.org/10.3102/0034654310364533

BOJE, T. Citizenship \& civil society: a Scandinavian perspective. In: Conference of Contemporary European Perspectives on Volunteering: Civic Virtue vs. Social Movement Activism, 2008, Ersta Sköndal University College (Stockholm).

BRANCO, M. L.; DOMINGUES, J. A. Currículo e cidadania. contributos para pensar a educação do cidadão no mundo globalizado. Rio de Janeiro: Dialogarts, 2015.

BROSTRÖM, A. Young or youthful: The Scout Movement and youth discourses. 
O escutismo na construção das cidadanias juvenis: concepções de política de jovens escuteiros e escuteiras

Leisure/Loisir, v. 36, n. 1, p. 53-64, jul. 2012. DOI: https://doi.org/10.1080/14927713.2012.701953

CAETANO, A. et al. Análise Multinível das Condições Estruturais da Educação para a Cidadania (EC) na Europa: as políticas Europeias de EC e as visões de organizações não-governamentais (ONG) no campo da EC. In: MENEZES, I.; FERREIRA, P. D. (Orgs.). Educação para a cidadania participatória em sociedades em transição: uma visão Europeia, Ibérica e Nacional das Políticas e Práticas da Educação para a Cidadania em Contexto Escolar. Porto: FPCEUP/CIIE, 2012. p. 17-41.

CNE. Corpo Nacional de Escutas. Regulamento Geral do CNE. Disponível em: $<$ https://www.escutismo.pt/dirigentes/associacao/regulamentos/regulamentos:113>. Acesso em: 11 maio 2013.

CNE. Corpo Nacional de Escutas. O que fazemos. 2016. Disponível em: $<$ https://escutismo.pt/quero-ser-escuteiro/o-que-fazemos/o-que-fazemos:133>. Acesso em: 20 jul. 2019.

CUNHA, O. Sentido psicológico de comunidade: um estudo multimétodo num contexto associativo. 2016. 250 f. Tese (Doutorado em Psicologia Comunitária) - Instituto Universitário de Psicologia Aplicada, Lisboa, 2016.

DELLI CARPINI, M. X.; KEETER, S. What Americans know about politics and why it matters. New Haven: Yale University Press, 1996.

DEWEY, J. Democracy and education. Carbondale: Southern Illinois University Press, [1916]1985.

ELIASOPH, N. Avoiding politics: how Americans produce apathy in everyday life. Cambridge: Cambridge University Press, 1998.

FAHMY, E. Social capital and civic action: A study of youth in the United Kingdom. Young, v. 14, n. 2, p. 101-118, maio 2006. DOI: https://doi.org/10.1177/1103308806062736

FERREIRA, P. D. Concepções de direitos ativos e experiências de participação na sociedade civil. 2006. 397 f. Tese (Doutorado em Psicologia) - Universidade do Porto, Porto, 2006.

FERREIRA, P. D.; COIMBRA, J. L.; MENEZES, I. "Diversity within Diversity": Exploring Connections between Community, Participation and Citizenship. Journal of Social Science Education, v. 11, n. 3, p. 120-134, jul. 2012. DOI: https://doi.org/10.4119/jsse-616

FLANAGAN, C. A. Volunteerism, leadership, political socialization, and civic engagement. In: LERNER, R. M.; STEINBERG, L. (Orgs.). Handbook of Adolescent Psychology. New York: Wiley, 2004. p. 721-746.

FREIRE, P. Pedagogia do oprimido. Rio de Janeiro: Paz e Terra, 1970. 
FRISCO, M. L., MULLER, C.; DODSON, K. Participation in Voluntary Youth-Serving Associations and Early Adult Voting Behavior. Social Science Quarterly, v. 8, n. 3, p. 660-676, set. 2004. DOI: https://www.jstor.org/stable/42955966

GIROUX, H. A. Ideology, culture, and the process of schooling. Philadelphia: Temple University Press, 1981.

GRANJA, S. F. C. Pedagogia escutista como complemento à educação escolar. 2007. Tese (Mestrado em Educação) - Universidade de Aveiro, Aveiro, 2007.

GUEST, G.; MACQUEEN, K. M.; NAMEY, E. E. Applied thematic analysis. Thousand Oaks: Sage, 2012.

HEDTKE, R. Who is afraid of non-conformist youth? The right to dissent and to not participate. In: HEDTKE, R.; ZIMENKOVA, T. (Orgs.). Education for civic and political participation: a critical approach. London: Routledge, 2013. p. 54-78.

HUCKFELDT, R.; IKEDA, K.; PAPPI, F. U. Patterns of disagreement in democratic politics: Comparing Germany, Japan and the United States. American Journal of Political Science, v. 49, n. 3, p. 497-514, may 2005. DOI: https://doi.org/10.1111/j.1540-5907.2005.00138.x

JABR, A. F. The Leadership Behaviour of Scouts and Guides in Nablus Schools. 1998. Disponível em: <http://scholar.najah.edu/content/leadership-behaviourscouts-and-guidesnablus- schools>. Acesso em: 2 abr. 2014.

JONES, E.; GAVENTA, J. Concepts of citizenship: a review. Brighton: Institute for Development Studies, 2002.

KAUFMAN, J. For the common good? American civic life and the golden age of fraternity. New York: Oxford University Press, 2002.

KIERSTEAD, J. Montessori and Dewey: a comparison of their theory and practice. 1980. Disponível em: <https://eric.ed.gov/?id=ED198506>. Acesso em: 20 jul. 2019.

LIMA, L. C. Organização escolar e democracia radical: Paulo Freire e a governação democrática da escola pública. São Paulo: Cortez Editora; Instituto Paulo Freire, 1999.

LISTER, R. et al. Young people talk about citizenship: empirical perspectives on theoretical and political debates. Citizenship Studies, v. 7, n. 2, p. 235-253, jul. 2003. DOI: https://doi.org/10.1080/1362102032000065991

MAHONEY, J. L. et al. Organized Activities as developmental contexts for children and adolescents. In: MAHONEY, J. L.; ECCLES, J. S. (Orgs.). Organized activities as developmental contexts: extracurricular activities after-school and community programs Mahwah: Lawrence Erlbaum, 2005. p. 3-22.

MAIA, R. L. Discípulos de Baden-Powell: sociologia das representações e das expectativas do escutismo em Portugal. Lisboa: Edições Universidade Fernando Pessoa, 2009. 
MALAFAIA, C. Living and doing politics: an educational travelogue through meanings, processes and effects. 2017. 323 f. Tese (Doutorado em Ciências da Educação) - Universidade do Porto, Porto, 2017.

MATLESS, D. Visual culture and geographical citizenship: England in the 1940s. Journal of Historical Geography, v. 22, n. 4, p. 424-439, oct. 1996. DOI: https://doi.org/10.1006/ihge.1996.0029

MAYOR, F. Guidisme et scoutisme, une culture de la paix. European Conference of the Girl Guide and Boy Scout Movement, Salzburg, Austria, 1995.

MCCOWAN, T. Rethinking citizenship education: A curriculum for participatory democracy. Londres: Continuum, 2009.

MEDINA, D. do R. Mediatização da comunicação política. Media, política e comunicação a negociação do poder. 2006.2 Disponível em: <https://minerva.usc.es/xmlui/bitstream/handle/10347/2398/9788471914644_content.pdf;jses sionid=5BEE6400C420C7A771091F1452D66385?sequence=1 >. Acesso em: 1 abr. 2014.

MENEZES, I. Participation experiences and civic concepts, attitudes and engagement: Implications for citizenship education projects. European Educational Research Journal, v. 2, n. 3, p. 430-445, set. 2003. DOI: https://doi.org/10.2304/eerj.2003.2.3.8

MENEZES, I. et al. Conhecimentos, conceções e práticas de cidadania dos jovens portugueses: um estudo internacional. Lisboa: Direcção-Geral de Inovação e Desenvolvimento Curricular, 2005.

MENEZES, I. et al. Agência e participação cívica e política: jovens e imigrantes na construção da democracia. Porto: Livpsic; Legis Editora, 2012.

MILLS, S. Duty to God/my Dharma/Allah/Waheguru: diverse youthful religiosities and the politics and performance of informal worship. Social \& Cultural Geography, v. 13, n. 5, aug. 2012. DOI: http://dx.doi.org/10.1080/14649365.2012.698749

MILLS, S. 'An instruction in good citizenship': Scouting and the historical geographies of citizenship education. Transactions of the Institute of British Geographers, v. 38, n. 1, p. 120-134, apr. 2013. DOI: https://doi.org/10.1111/j.1475-5661.2012.00500.x

PALHARES, J. A. Jovens, experiência social e escutismo. Contributo para uma sociologia da educação não-escolar. 2004. Tese (Doutorado em Educação) - Universidade do Minho, Braga, 2004.

PALHARES, J. A. Os sítios de educação e socialização juvenis: experiências e representações num contexto não-escolar. Educação, Sociedade \& Culturas, Porto, n. 27, p. 109-130, 2008.

PARRY, G.; MOYSER, G.; DAY, N. Political participation and democracy in Britain. Cambridge: Cambridge University Press, 1992. 
PRILLELTENSKY, I. Understanding, Resisting, and overcoming oppression: toward psychopolitical validity. American Journal of Community Psychology, v. 31, n. 1-2, p. 195201, mar. 2003. DOI: https://doi.org/10.1023/A:1023043108210

PROCTOR, T. Introduction: building and empire of youth: Scout and guide history in perspective. In: BLOCK, N.; PROCTOR, T. (Orgs.). Scouting frontiers: youth and the scout movement's first century. Newcastle: Cambridge Scholars Publishing, 2009. p. xxvi-xxxviii.

PUTNAM, R. Bowling alone. the collapse and revival of American democracy. Nova Iorque: Simon \& Schuster, 2000.

PUTNAM, R. Making democracy work: Civic traditions in Modern Italy. Princeton: Princeton University Press, 1993.

QUINTELIER, E. Who is politically activist?: Young people, voluntary engagement and political participation who is politically active: the athlete, the scout member or the environmental. Acta Sociologica, v. 51, n. 4, p. 355-370, dec. 2008. DOI: https://www.jstor.org/stable/20460071

RIBEIRO, N. Educação para a cidadania em Portugal: contributos para analisar a sua evolução no currículo escolar português. Currículo sem Fronteiras, v. 14, n. 3, p. 12-31, set./dez. 2014.

RODRIGUES, M. O escutismo na construção das cidadanias juvenis: estudo sobre educação e participação de jovens escuteiros e escuteiras. 2019. 296 f. Tese (Doutorado em Ciências da Educação) - Universidade do Porto, Porto, 2019.

RODRIGUES, M.; MENEZES, I.; FERREIRA, P. D. The organisational and educational contexts of the Portuguese Catholic Scout Association: Their impact on youth participation. Italian Journal of Sociology of Education, v. 7, n. 1, p. 148-175, feb. 2015.

RODRIGUES, M.; MENEZES, I.; FERREIRA, P. D. Efeitos longitudinais de agentes de socialização política nos comportamentos de participação de jovens. Educação e Pesquisa, São Paulo, v. 44, e175560, p. 1-20, jul. 2018. DOI: http://dx.doi.org/10.1590/s1678$\underline{4634201844175560}$

RUIZ-OLIVARES, R.; PINO, M. J.; HERRUZO, J. Assessment of prosocial-altruistic behavior of members and non-members of the scout movement. European Journal of Psychology Education, v. 28, n. 2, p. 189-199, fev. 2013. DOI: https://doi.org/10.1007/s10212-012-0109-6

RUSSEL, A. The truth about youth? Media portrayals of young people and politics in Britain. Journal of Public Affairs, v. 4, n. 4, p. 347-354, jul. 2004. DOI: https://doi.org/10.1002/pa.197

SCHULZ, W. et al. Initial findings from the IEA International Civic and Citizenship Education Study. Amsterdam: International Association for the Evaluation of Educational Achievement, 2010.

SEHR, D. T. Education for public democracy. Nova York: SUNY Press, 1997.

SPRINGHALL, J. Youth, empire and British society: British youth movements, 1883-1940. London: Croom Helm, 1977. 
SULLIVAN, J. L.; TRANSUE, J. E. The psychological underpinnings of democracy: a selective review of research on political tolerance, interpersonal trust, and social capital. Annual Review of Psychology, v. 50, p. 625-650, fev. $1999 . \quad$ DOI: https://doi.org/10.1146/annurev.psych.50.1.625

SUNDMARK, B. Citizenship and Children's Identity in The Wonderful Adventures of Nils and Scouting for Boys. Children's Literature in Education, v. 40, n. 2, p. 109-119, jan. 2009. DOI: https://doi.org/10.1007/s10583-008-9081-9

THEISS-MORSE, E.; HIBBING, J. Citizenship and civic engagement. Annual Review of Political Science, n. 8, p. 227-249, jun. $2005 . \quad$ DOI: https://doi.org/10.1146/annurev.polisci.8.082103.104829

TOOTS, A. Motivated by education or encouraged by opportunities? A comparative perspective on knowledge and participation nexus. In: HEDTKE, R.; ZIMENKOVA, T. (Orgs.). Education for civic and political participation: a critical approach. Londres: Routledge, 2013. p. $99-116$.

VAN DER MEER, T.; VAN INGEN, E. Schools of Democracy? Disentangling the relationship between civic participation and political action in 17 European countries. European Journal of Political Research, v. 48, n. 2, p. 281-308, fev. 2009. DOI: https://doi.org/10.1111/j.1475$\underline{6765.2008 .00836 . x}$

VANHOENACKER, M. Education in a French secular group of scouts: a site to study tensions over citizenship. Citizenship Studies, v. 15, n. 8, p. 1047-1059, jan. 2011. DOI: https://doi.org/10.1080/13621025.2011.627770

VICENTE, A. C. da S. D. A introdução do escutismo em Portugal: 1911-1942. Disponível em: <http://repositorio.ucp.pt/bitstream/10400.14/4476/1/LS_S2_16_AnaCSDVicente.pdf>. Acesso em: 23 maio 2015

WARREN, A. Foreword. In: BLOCK, N.; PROCTOR, T. (Orgs.). Scouting frontiers: Youth and the Scout Movement's first century. Newcastle: Cambridge Scholars Publishing, 2009. p. xixxii.

WARREN, M. E. Democracy and association. Princeton: Princeton University Press, 2001.

WATTS, R. J.; FLANAGAN, C. A. Pushing the envelope on youth civic engagement: a developmental and liberation psychology perspective. Journal of Community Psychology, v. 35, n. 6, p. 779-792, jun. 2007. DOI: https://doi.org/10.1002/jcop.20178

WESTHEIMER, J.; HAHNE, J. What kind of citizen? The politics of educating for democracy. American Educational Research Journal, v. 41, n. 2, p. 1-26, jun./set. 2004.

WITTEMANS, S. The double concept of citizen and subject at the heart of guiding and scouting. In: BLOCK, N.; PROCTOR, T. (Orgs.). Scouting frontiers: Youth and the Scout Movement's first century. Newcastle: Cambridge Scholars Publishing, 2009. p. 56-71. 
YOUNISS, J.; YATES, M. Community service and political moral identity in adolescents. Journal of Research on Adolescence, v. 6, n. 3, p. 271-284, abr. 1996. DOI: https://doi.org/10.1111/j.1540-4560.1998.tb01232.x

ZALLER, J. R. The nature and origins of mass opinion. New York: Cambridge University Press, 1992.

ZIMENKOVA, T. sharing political power or caring for the public good? The impact of service learning on civic and political participation. In: HEDTKE, R.; ZIMENKOVA, T. (Orgs.). Education for civic and political participation: a critical approach. London: Routledge, 2013. p. 171-188.

Recebido em 31/03/2019

Versão corrigida recebida em 22/08/2019

Aceito em 24/08/2019

Publicado online em 03/09/2019 